\title{
Socioeconomic - related inequalities in overweight and obesity: findings from the PERSIAN cohort study
}

Farid Najafi ${ }^{1,2}$, Shahin Soltani ${ }^{1,2^{*}}$ (D), Behzad Karami Matin ${ }^{1,2}$, Ali Kazemi Karyani ${ }^{1,2}$, Satar Rezaei ${ }^{1}$, Moslem Soofi ${ }^{2}$, Yahya Salimi², Mehdi Moradinazar ${ }^{1}$, Mohammad Hajizadeh³, Loghman Barzegar ${ }^{1}$, Yahya Pasdar ${ }^{1}$, Behrooz Hamzeh ${ }^{1}$, Ali Akbar Haghdoost ${ }^{4}$, Reza Malekzadeh, Hossein Poustchi ${ }^{5}$, Sareh Eghtesad ${ }^{5}$,

Azim Nejatizadeh ${ }^{6}$, Mahmood Moosazadeh ${ }^{7}$, Mohammad Javad Zare Sakhvidi ${ }^{8}$, Farahnaz Joukar ${ }^{9}$, Seyed Mohammad Hashemi-Shahri ${ }^{10}$, Alireza Vakilian ${ }^{11}$, Ramin Niknam ${ }^{12}$, Elnaz Faramarzi ${ }^{13}$, Ghodrat Akhavan Akbari ${ }^{14}$, Fershteh Ghorat ${ }^{15}$, Arsalan Khaledifar ${ }^{16}$, Davoud Vahabzadeh ${ }^{17}$, Reza Homayounfar ${ }^{18}$, Ali Reza Safarpour ${ }^{12}$, Sayed Vahid Hosseini ${ }^{19}$, Reza Rezvani ${ }^{20}$ and Seyyed Ahmad Hosseini ${ }^{21}$

\begin{abstract}
Background: Overweight and obesity are major health concerns worldwide, with adverse health consequences during the life span. This study measured socioeconomic inequality in overweight and obesity among Iranian adults.
\end{abstract}

Methods: Data were extracted from 129,257 Iranian adults (aged 35 years and older) participated in the Prospective Epidemiologic Research Studies in IrAN (PERSIAN) in 14 provinces of Iran in 2014. Socioeconomic-related inequality in overweight and obesity was estimated using the Concentration Index $\left(C_{n}\right)$. The $C_{n}$ further decomposed to find factors explaining the variability within the Socioeconomic related inequality in overweight and obesity.

Results: Of the total number of participants, 1.98, 26.82, 40.76 and 30.43\% had underweight, normal weight, overweight and obesity respectively. The age-and sex standardized prevalence of obesity was higher in females than males (39.85\% vs 18.79\%). People with high socioeconomic status (SES) had a 39 and 15\% higher chance of being overweight and obese than low SES people, respectively. The positive value of $C_{n}$ suggested a higher concentration of overweight $(0.081,95 \%$ confidence interval [Cl]; 0.074-0.087) and obesity $(0.027,95 \% \mathrm{Cl} ; 0.021-$ 0.034) among groups with high SES. There was a wide variation in socioeconomic-related inequality in overweight and obesity rate across 14 provinces. The decomposition results suggested that SES factor itself explained 66.77 and 89.07\% of the observed socioeconomic inequalities in overweight and obesity among Iranian adults respectively. Following SES, province of residence, physical activity, using hookah and smoking were the major contributors to the concentration of overweight and obesity among the rich.

Conclusions: Overall, we found that overweight and obesity is concentrated among high SES people in the study population. . Accordingly, it seems that intersectional actions should be taken to control and prevent overweight and obesity among higher socioeconomic groups.

Keywords: Socioeconomic Factors, Inequality, Concentration index, overweight and obesity, PERSIAN, Iran

\footnotetext{
* Correspondence: sh-soltani@alumnus.tums.ac.ir

${ }^{1}$ Research Center for Environmental Determinants of Health, Health Institute,

Kermanshah University of Medical Sciences, Kermanshah, Iran

${ }^{2}$ Social Development and Health Promotion Research Center, Kermanshah

University of Medical Sciences, Kermanshah, Iran

Full list of author information is available at the end of the article
}

(c) The Author(s). 2020, corrected publication 2022. Open Access This article is distributed under the terms of the Creative Commons Attribution 4.0 International License (http://creativecommons.org/licenses/by/4.0/), which permits unrestricted use, distribution, and reproduction in any medium, provided you give appropriate credit to the original author(s) and the source, provide a link to the Creative Commons license, and indicate if changes were made. The Creative Commons Public Domain Dedication waiver (http://creativecommons.org/publicdomain/zero/1.0/) applies to the data made available in this article, unless otherwise stated. 


\section{Background}

Obesity is one of the major health concerns worldwide affecting approximately all physiological roles of the body. It increases the risk for multiple chronic conditions, such as cardiovascular disease [1,2], diabetes mellitus [1], different kinds of cancers [3], some musculoskeletal disorders [4], and poor mental health [5]. Also, studies show that obesity can have negative influences on the quality of life, healthcare costs and work productivity $[6,7]$. The World Health Organization (WHO) has estimated that obesity affects 500 million people worldwide and it could potentially increase to one billion people globally by $2030[8,9]$.

Although overweight and obesity result from a combination of causes, over-consumption of high-energy foods is considered as the primary cause of obesity [10]. In addition, evidence showed that factors such as lack of physical activity, lack of sleep, sedentary lifestyle and high level of stress could also increase the risk of obesity $[11,12]$. Iindividual, social and behavioral determinates of obesity $[13,14]$ may increase the risk of obesity conjointly or independently. For example, an obesogenic behavior like lack of physical activity may be influenced by individual and social factors such as genetic, biological, marital, educational and occupational factors $[15,16]$.

The existing literature repeatedly has investigated the effects of education and income, as indicators for socioeconomic status (SES), on obesity in both developed and developing countries. Some studies suggested that low education and income can put individuals at the risk of obesity in developed countries [17, 18]. For example, findings of a study in Germany showed that lesseducated and low-income people tended to be more obese than their respective counterparts [19]. In contrast, systematic reviews of the current studies revealed a strong positive association between SES and obesity in countries with low human development index (HDI) for both men and women [20]. Accordingly, the study by Dinsa et al. notes that higher educational attainment increases the probability of obesity among the general population [17].

To date, several studies have been conducted to investigate the socioeconomic determinants of obesity, including education, income, occupational status and place of residence in an Iranian population. The results of available studies show consistent findings of the association between socioeconomic factors and overweight and obesity [21-23]. For instance, Bakhshi et al. in a national health survey found that higher education and active workforce decrease the odds of obesity and in contrast higher income and urbanization increase the risk of obesity among both Iranian males and females [22]. Also, Kolahi et al. in a nationwide survey in 31 provinces of Iran found that the socioeconomic factors such as urbanization, living alone, being housewife or retired, and having lower education were associated with overweight and obesity [24].

Although the current studies assessed the effect of different socioeconomic factors on overweight and obesity in Iran, there are limited numbers of studies $[25,26]$ aimed to quantify socioeconomic inequalities in overweight and obesity in certain provinces of Iran. Accordingly, the main aim of the present study was to measure socioeconomic inequalities in overweight and obesity and then to identify the major contributors to the measured inequality in the outcome variables. Additionally, using the Prospective Epidemiologic Research Study in IRaN (PERSIAN Cohort Study), we identified the risk factors of, and geographical differences in overweight and obesity among adults in 14 provinces in Iran.

\section{Method}

\section{Data source and variables}

Data were extracted from the Prospective Epidemiological Research Studies in IrAN (PERSIAN), which collects epidemiological information from 17 cohort centers in 14 provinces in Iran since 2014. The cohort population for each province has been presented in Table 3. Other detailed information on the cohort method can be found in the past studies [27, 28].

According to statistical census center in 2016, the population of Iran was 79,926,270. Iran has 31 provinces and located in western Asia with a total area of $1,648,195 \mathrm{~km}^{2}$. Our study population approximately included $0.16 \%$ of Iran population.

Overall 129,257 Iranian adults aged 35 to 70 years participated in this cohort study. The mean age of the cohort population was 49.41 years \pm 9.18 . In all study provinces, participants were recruited from urban settings and entered in the study by multistage cluster sampling. Following identifying households in each cluster, all individuals aged 35 to 70 years who lived in a household included in the study according to the inclusion and the exclusion criteria.

The inclusion criteria in the cohort study included:

1. General population aged 35 to 70 years

2. Households located within the study area

3. People with Iranian nationality

Also, exclusion criteria included:

1. People who were reluctant to participate in the study.

2. People with communication disorders who were not able to answer the study questions

3. People with hearing and intellectual disability, mental disorders, and vision loss. 
In the study, the outcome variables were a binary variable indicating whether the participant had overweight (Body Mass Index $(\mathrm{BMI})=25-29.9 \mathrm{~kg} / \mathrm{m} 2$ ) and obesity $(\mathrm{BMI} \geq 30 \mathrm{~kg} / \mathrm{m} 2)$ [29]. Also, BMI less than 18.5 and 18.5-24.9 were classified as underweight and normal weight respectively. Several sociodemographic (age, sex, marital status), socioeconomic, behavioral (physical activity, cigarette smoking, hookah smoking, alcohol consumption and drug abuse) and geographical factors were used as determinants of overweight and obesity in the analysis. Physical activity was measured on a weekly basis using Metabolic Equivalent Rates (METs) of selfreported daily activities of participants. One MET is equal to resting metabolic rate, the amount of oxygen consumed at rest that is about $3.5 \mathrm{ml}$ of oxygen per kilogram per minute. Given that four METs requires $16 \mathrm{ml}$ oxygen/kilogram/minute [30], MET of each activity were extracted using compendium of physical activities [31, 32]. With regard to the mean MET rates of participants (41 METs/hour/day), participants with less than 41 METs/hour/day were defined as individuals with poor physical activity level. In the present study, alcohol consumers were individuals who used at least 12 drinks in the past year [33]. Also, drug abuse was defined as lifetime use of any kinds of illicit drugs (e.g. opium, heroin, cocaine, crack, etc.).

Concerning the definition of smoking provided in the National Health Interview Survey (NHIS), current smokers were individuals who smoked 100 cigarettes in their lifetime and who currently smoke cigarettes regularly. The former smokers were defined as people who have quit cigarette and/or tobacco use [34]. Furthermore, Hookah (water pipe used to smoke flavored tobacco) smoking was defined as at least one session per month [35]. In the cohort study, the variables of drug abuse, alcohol consumption and hookah smoking were measured by a self-report questionnaire.

Regarding the difficulties in estimating SES with income and consumption, past studies have focused on developing proxy indicators. In global health research, the wealth index has been proposed as one of the most important key proxy indicators [36]. For example, some researchers have applied the wealth index to investigate subjects such as malnutrition [37], prenatal care [38], malaria transmission [39], reproductive health [40], and poverty [41].

In the present study, given available data, we used information on assets ownership (e.g., owning car, motorcycle, bicycle, refrigerator, stove, vacuum machine, personal computer, sewing machine and washing mashing), housing characteristics (e.g. bathroom, house area per capita) and education level of participants to create SES variable. Therefore, the SES indicator was constructed by a combination of households' assets and education levels of participants following a procedure developed by Filmer and
Pritchett [42] based on principal components analysis (PCA). In this study, this method was used to reduce multi-dimensional data sets on ownership of different household assets to a lower number of dimensions.

As socioeconomic status (SES) was an important determinant to measure inequality in overweight and obesity, we performed the principal component analysis (PCA) to construct a rank variable when we measured socioeconomic-related inequality [43]. Participants were categorized into five SES quintile from the lowest (1st quintile) to highest (5th quintile) SES groups.

\section{Statistical analysis}

Socioeconomic-related inequality in overweight and obesity The Concentration index $(\mathrm{Cn})$ measures inequality in the outcome variable (e.g. obesity) over the distribution of an explanatory variable (e.g. socioeconomic status). In fact, the concentration index indicates the extent to which our outcomes (overweight and obesity) differs across individuals ranked by SES [44]. The $C_{n}$ is based on the concentration curve which graphs the cumulative percentage of a population according to their SES on the horizontal axis and the cumulative percentage of health outcome (overweight and obesity) on the vertical axis. The $C_{n}$ is twice the area between the concentration curve and line of perfect equality (the 45-degree diagonal line). The value of the $C_{n}$ varies between -1 and +1 . The numbers -1 and +1 show the highest socioeconomic related inequality among a population. The negative value of the $C_{n}$ suggests the concentration of the health outcome among the poor and vice versa. The zero value of the $C_{n}$ reveals equal socioeconomic distribution of the health outcome among the different SES groups. The $C_{n}$ can be measured using following "convenient covariance" formula [45]:

$$
c=\frac{2 * \operatorname{cov}\left(y_{i} r_{i}\right)}{\mu}
$$

where $y_{i}$ is health outcome variable (i.e., overweight and obesity) for participant $i, r_{i}$ is the fractional rank of participant $i$ in the distribution of SES indicator, $\mu$ is the mean of the health outcome variable. As overweight and obesity is a binary variable, the minimum and maximum of the $\mathrm{C}$ are not -1 and +1 . Thus, as per Wagstaff suggestion [46], we normalized the $C_{n}$ as:

$$
C_{n}=\frac{1}{1-\mu}
$$

\section{Decomposition of socioeconomic inequality in overweight and obesity}

The estimated value of the normalized $C_{n}$ was decomposed to identify the contribution of explanatory 
variables to the observed socioeconomic inequality in overweight and obesity [47]. Wagstaff and colleagues [47] noted that if we have a regression model relating a health outcome variable of $y$ to a set of $k$ explanatory variables, $x$, such as:

$$
y=a+\sum_{k} \beta_{k} X_{k}+\varepsilon
$$

the $C_{n}$ for $y$ can be decomposed as:

$$
C=\sum_{k}\left(\frac{\beta_{k} \overline{X_{k}}}{\mu}\right) C_{k}+G C_{\varepsilon} / \mu
$$

In this equation, $\bar{x}_{k}$ denotes the mean of the explanatory variable, $x, C_{k}$ is the $C_{n}$ for each explanatory variable, $G C_{\varepsilon}$ is the generalized $C_{n}$ for $\varepsilon$. The first component in equation $4, \sum_{k}\left(\frac{\beta_{k} \bar{x}_{k}}{\mu}\right) C_{k}$ indicates the contribution of explanatory variable $x$ to the overall socioeconomic-related inequality in the health outcome. The negative (positive) contribution of an independent variable indicates that the SES-related distribution of this variable and its relation with overweight and obesity increase the concentration of overweight and obesity among the poor (the rich). The second component in equation $4, \frac{G C_{\varepsilon}}{\mu}$ shows the proportion of socioeconomic inequality in overweight and obesity which is not explained by the systematic variation of the included explanatory variables across SES groups. Applying Wagstaff's correction into Equation [46] yields to:

$$
C_{n}=\frac{C}{1-\mu}=\frac{\sum_{k}\left(\frac{\beta_{k} \bar{x}_{k}}{\mu}\right) C_{k}}{1-\mu}+\frac{G C_{\varepsilon} / \mu}{1-\mu}
$$

As overweight and obesity is a binary variable, we used marginal effects obtained from a logistic model as $\beta$ in the decomposition of the $C_{n}$. All the analyses were performed using Stata version 14.2 (StataCorp, College Station, TX, USA).

Also, adjusted Odds ratio (OR) with 95\% CI was applied to measure the association between the determinants and the outcome variables among the cohort population. Accordingly, the conceptual framework that guided our analysis was developed by Malik and $\mathrm{Hu}$ (Fig. 1) [48]. According to available data, we included socioeconomic and cultural factors (age, gender, marital status and SES), individual behaviors (cigarette and hookah smoking, drug abuse, and alcohol consumption) and physical activity. Also, the region of residence was included in our analysis as a macrolevel factor.

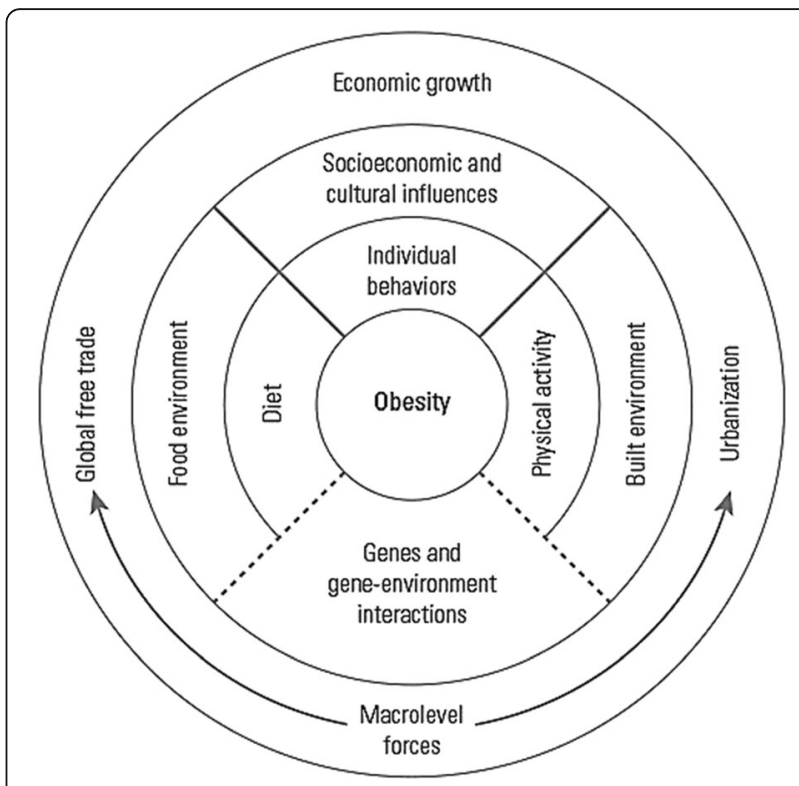

Fig. 1 Determinants of obesity (developed by Malik and Hu (2017))

\section{Results}

\section{Prevalence of overweight and obesity}

Table 1 reports the crude prevalence, age-and sexstandardized prevalence and adjusted OR for outcome variables by characteristics of participants. The prevalence of underweight, normal weight, overweight and obesity was $1.98,26.82,40.76$ and $30.43 \%$ in the present study respectively. Of the total of 129 , 257 adults participated in the study, 57,614(44.57\%) were males and 71,643(55.43\%) were females. Although women had the higher age-standardized prevalence $(39.85 \%$ vs $18.79 \%)$ and odds (OR: 2.83, 95\% CI: $2.73-2.92)$ of obesity than men, they indicated the lower age-standardized prevalence (38.98\% vs $42.98 \%$ ) and odds (OR: 0.78, 95\% CI: 0.82-0.86) of overweight compared to men. Participants in the age groups of 35-44 years and 45-54 years had the highest sex-standardized prevalence of overweight $(41.47 \%)$ and obesity $(33.38 \%)$ respectively.

The cohort of Ardabil had the highest age-and sex-standardized prevalence $(46.82 \%)$ and odds (OR: 2.05, 95\% CI: $1.92-2.19)$ of obesity in comparison to other provinces. Although, Razavi Khorasan had the highest age-and sex-standardized prevalence (46.82\%) of overweight, the cohort population in Chaharmahal and Bakhtiari had the highest odds of overweight (OR: 1.02, 95\% CI: 0.96-1.09) compared to other study provinces. Fig. 2 shows the age-and sexstandardized prevalence of underweight, normal weight, overweight and obesity in the included population. 
Table 1 Prevalence of overweight and obesity by characteristics of participants

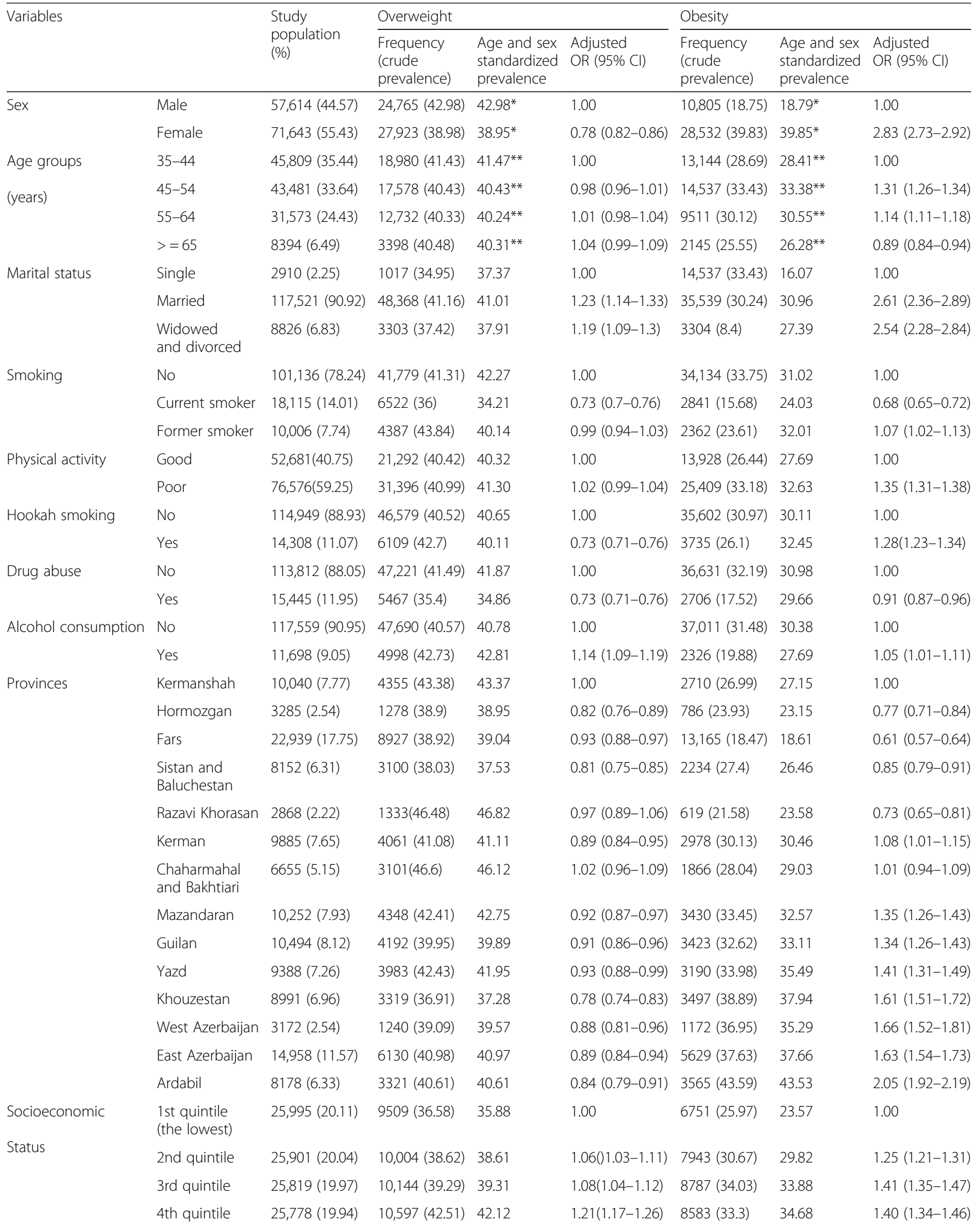


Table 1 Prevalence of overweight and obesity by characteristics of participants (Continued)

\begin{tabular}{|c|c|c|c|c|c|c|c|c|}
\hline \multirow[t]{2}{*}{ Variables } & & \multirow{2}{*}{$\begin{array}{l}\text { Study } \\
\text { population } \\
(\%)\end{array}$} & \multicolumn{3}{|l|}{ Overweight } & \multicolumn{3}{|l|}{ Obesity } \\
\hline & & & $\begin{array}{l}\text { Frequency } \\
\text { (crude } \\
\text { prevalence) }\end{array}$ & $\begin{array}{l}\text { Age and sex } \\
\text { standardized } \\
\text { prevalence }\end{array}$ & $\begin{array}{l}\text { Adjusted } \\
\text { OR (95\% Cl) }\end{array}$ & $\begin{array}{l}\text { Frequency } \\
\text { (crude } \\
\text { prevalence) }\end{array}$ & $\begin{array}{l}\text { Age and sex } \\
\text { standardized } \\
\text { prevalence }\end{array}$ & $\begin{array}{l}\text { Adjusted } \\
\text { OR }(95 \% \mathrm{Cl})\end{array}$ \\
\hline & $\begin{array}{l}\text { 5th quintile } \\
\text { (the highest) }\end{array}$ & 25,764 (19.93) & $12,074(46.86)$ & 45.75 & $1,39(1.33-1.45)$ & $7273(28.23)$ & 31.28 & $1.15(1.11-1.21)$ \\
\hline Total & & $129,257(100)$ & $52,688(40.76)$ & & & $39,337(30.43)$ & & \\
\hline
\end{tabular}

* Sex comparisons are standardized for age. ${ }^{* *}$ Age comparisons are standardized for sex

Regarding Table 1, being married, widowed and divorced (compared to singles), and higher SES significantly increased the probability of overweight among the cohort population. On the other side, being female, being older, being married, widowed and divorced (compared to singles), former smoking, poor physical activity, alcohol consumption and higher SES significantly increased the probability of obesity among participants in the present study.

\section{Socioeconomic inequalities in overweight and obesity}

In this study, the positive value of the $C_{n}\left(C_{n}=\right.$ 0.027, 95\% CI: $0.021,0.034)$ for total provinces indicated the higher concentration of obesity among high-SES adults in the study population. The estimated value of the $C_{n}$ was positive in 7 provinces and negative in the remaining for 7 provinces. The highest concentration of obesity among the high SES and the low SES groups was observed in Khouzestan $\left(C_{n}=0.097,95 \%\right.$ CI: $\left.0.073,0.121\right)$ and Razavi Khorasan $\left(C_{n}=-0.087,95 \% \mathrm{CI}:-0.131,-0.451\right)$ provinces, respectively. Similarly, the $C_{n}$ for overweight was positive which indicate overweight is concentrated among high SES individuals. Fig. 3 illustrates the variation in socioeconomic inequality in overweight and obesity among Iranian provinces.

\section{Decomposition of socioeconomic inequality in overweight and obesity}

Turning to the contribution results reported in Table 2, it is evident that the SES factor explained 66.77 and $89.07 \%$ of the overall socioeconomic inequality in overweight and obesity respectively. Following SES, province of residence was the second largest contributor to the concentration of overweight and obesity among the rich and explained 22.62 and $56.19 \%$ of the overall socioeconomic inequality in overweight and obesity respectively. Physical activity level had a positive influence on the overall inequality, and it explained 9.42 and $22.74 \%$ of the observed inequality in overweight and obesity among the cohort population, respectively. Although gender and age made positive contributions to socioeconomic inequality in obesity, they made a negative contribution to socioeconomic related inequalities in overweight. Also, the decomposition analysis showed that cigarette smoking and hookah use (obesity only) were the main positive contributor to the observed inequality in overweight and obesity among the study population (Table 2).

\section{Discussion}

Using information derived from the PERSIAN Cohort Study, we analyzed overweight and obesity among Iranian adults aged 35 years and older. Specifically, we measured and decomposed socioeconomic inequalities in overweight and obesity in Iran. Our descriptive results suggested $18.75 \%$ of men and $39.83 \%$ for women had obesity in the included population. There was also substantial variation in the prevalence of obesity across included provinces.

The results of our study suggested that overweight and obesity were concentrated among the high SES adults in the cohort population as a whole. In agreement with our findings, the previous studies in Iran showed that obesity was less prevalent among lowSES people. For example, Najafi et al. found lower obesity prevalence among poor people in an sample of the Iranian population [25]. Also, Mohammedi et al. (2011) found that income had a positive association with obesity [49]. On the contrary, some studies indicate that people with lower education levels tend to be more obese than their counterparts with higher education [50].

Among the study provinces, Chaharmahal and Bakhtiari and Khouzestan had the lowest and the highest value of $C_{n}$. This finding shows that in Chaharmahal and Bakhtiari and Khouzestan distribution of obesity is disproportionately borne by the low and high SES individuals respectively. This result probably indicates that participants with higher SES in Khouzestan are more likely to have a sedentary lifestyle and an unhealthy dietary pattern in comparison to their counterparts in Chaharmahal and Bakhtiari. Some studies in Khouzestan indicated that lower educational levels, low physical activity, 


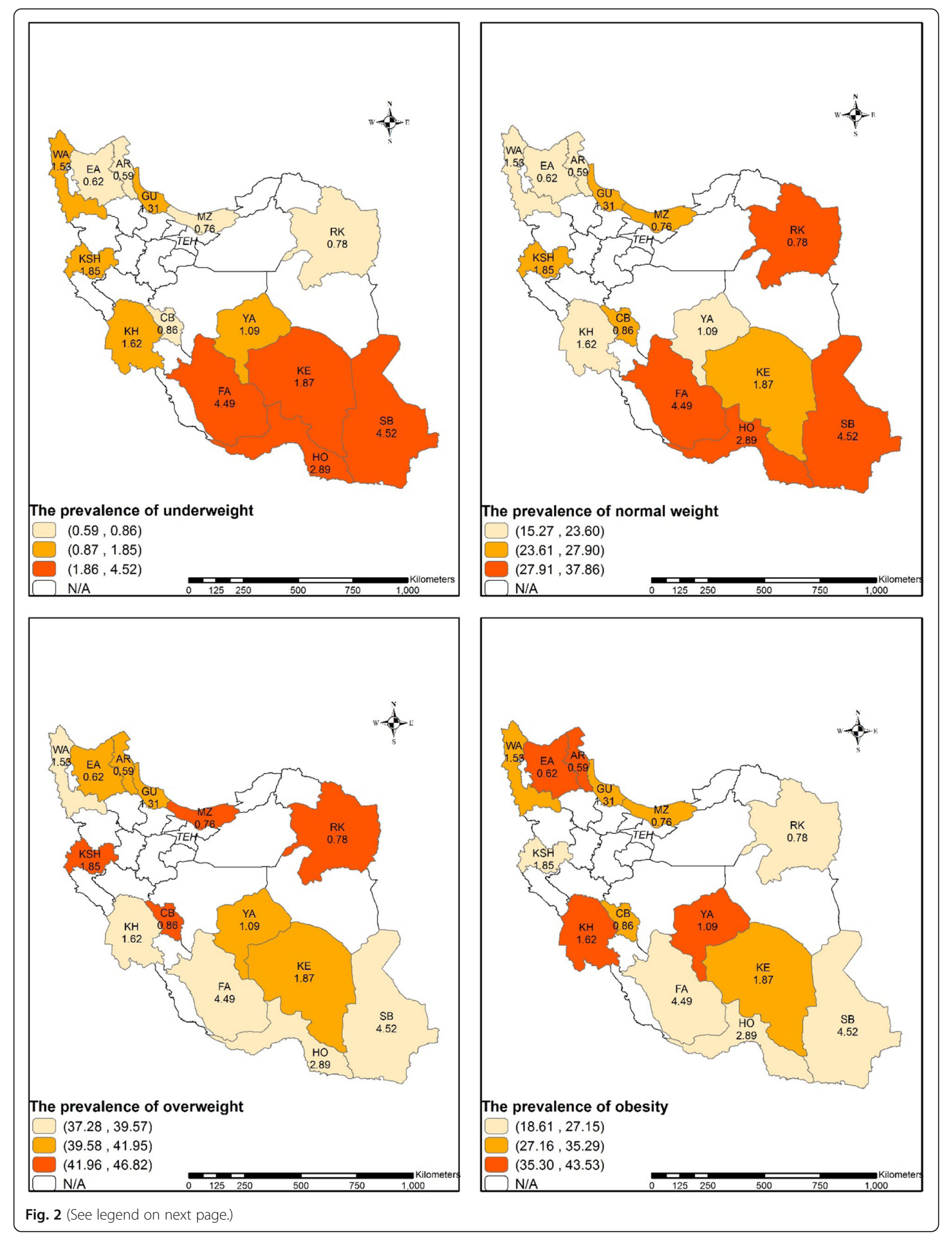


(See figure on previous page.)

Fig. 2 the age-and sex-standardized prevalence of underweight, normal weight, overweight and obesity among the study provinces (Razavi Khorasan(RK), Chaharmahal and Bakhtiari(CB), Yazd(YA), East Azarbaijan(EA), Ardabil(AR), West Azarbaijan(WA), Kerman(KE), Guilan(GU), Hormozgan(HO), Fars(FA), Kermanshah(KSH), Sistan and Baluchestan(SB), Mazandaran(MA), Khouzestan(KH))(developed by the authors using ArcGIS Desktop version 10.7)

food habits and sedentary lifestyle could be the major causes of obesity in both men and women in Khouzestan [51-53].

Additionally, factors such as cultural, environmental and regional climate diversities presumably can contribute to the observed differences in this socioeconomic inequality. Khouzestan is located in the south-west of Iran and has a hot desert climate [54]. In this province, day time temperatures in most parts reach above $50{ }^{\circ} \mathrm{C}$ during dry seasons which in turn can affect the levels of physical activity and dietary patterns among individual with higher SES. In other words, individuals with higher SES might prefer to spend more time at home and have less physically activity compared to their peers in other provinces.

According to our findings, SES, region of residence, physical activity, cigarette smoking, and hookah smoking (only for obesity) were the main positive contributors to socioeconomic-related inequality in overweight and obesity. Consistent with our results, literature in both developed and developing countries indicates that the factors such as income, marital status, education and physical activity were the major factors explaining socioeconomicrelated inequality in obesity $[25,55-57]$. In contrast, some studies note that factors such as genetic determinants, environment features, race and family history of obesity can explain the concentration of obesity in a population that should be examined in future studies [58-60].

In the present study, SES was the largest contributing factor to the inequality of overweight and obesity. The positive contribution demonstrates that SES has a major role in the disproportionate distribution of overweight and obesity among the study

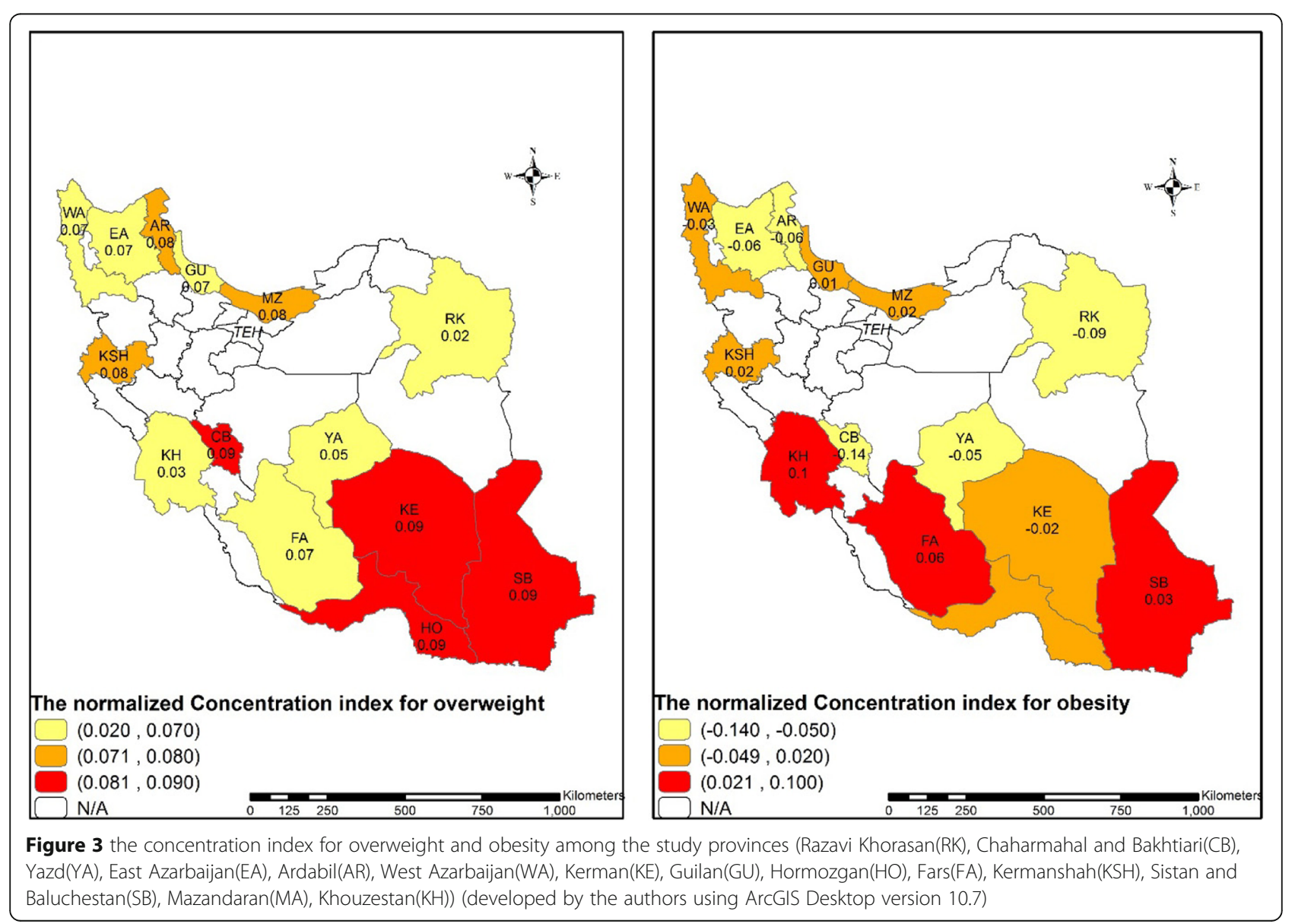


Table 2 Decomposition of socioeconomic inequality in overweight and obesity in the included population

\begin{tabular}{|c|c|c|c|c|c|c|c|c|c|}
\hline \multirow[t]{2}{*}{ Variables } & & \multicolumn{4}{|c|}{ Overweight } & \multicolumn{4}{|l|}{ Obesity } \\
\hline & & Elasticity & $\begin{array}{l}\text { Concentration } \\
\text { index }\left(C_{k}\right)\end{array}$ & $\begin{array}{l}\text { percentage } \\
\text { contribution }\end{array}$ & $\begin{array}{l}\text { Summed } \\
\text { Percentage } \\
\text { Contribution }\end{array}$ & Elasticity & $\begin{array}{l}\text { concentration } \\
\text { Index }\left(C_{k}\right)\end{array}$ & $\begin{array}{l}\text { percentage } \\
\text { contribution }\end{array}$ & $\begin{array}{l}\text { Summed } \\
\text { Percentage } \\
\text { Contribution }\end{array}$ \\
\hline \multirow[t]{2}{*}{ Sex } & male & & & & -3.74 & & & & 3.53 \\
\hline & female & 0.082 & -0.025 & -3.74 & & 0.338 & 0.006 & 3.530 & \\
\hline \multirow[t]{4}{*}{ Age } & $35-44$ & & & & -1.38 & & & & 3.29 \\
\hline & $45-54$ & 0.028 & 0.031 & 1.52 & & 0.061 & 0.035 & 4.012 & \\
\hline & $55-64$ & 0.013 & -0.134 & -3.02 & & 0.019 & -0.128 & -4.471 & \\
\hline & $>=65$ & 0.000 & -0.315 & 0.12 & & -0.006 & -0.317 & 3.745 & \\
\hline \multirow[t]{3}{*}{ Marital status } & single & & & & 2.91 & & & & 4.64 \\
\hline & married & 0.329 & 0.021 & 12.23 & & 0.565 & 0.021 & 22.741 & \\
\hline & $\begin{array}{l}\text { others (widow, } \\
\text { divorced) }\end{array}$ & 0.019 & -0.267 & -9.32 & & 0.042 & -0.230 & -18.106 & \\
\hline \multirow[t]{3}{*}{ Smoking status } & never smoked & & & & 6.34 & & & & 9.97 \\
\hline & current smoker & -0.039 & -0.091 & 6.38 & & -0.048 & -0.115 & 10.396 & \\
\hline & Former smoker & 0.001 & -0.036 & -0.04 & & 0.004 & -0.063 & -0.426 & \\
\hline \multirow[t]{2}{*}{ Use Hookah } & no & & & & 2.06 & & & & 27.89 \\
\hline & yes & 0.009 & 0.123 & 2.06 & & 0.145 & 0.103 & 27.887 & \\
\hline \multirow[t]{2}{*}{ Drug abuse } & no & & & & 3.75 & & & & 3.04 \\
\hline & yes & -0.020 & -0.104 & 3.75 & & -0.014 & -0.120 & 3.043 & \\
\hline \multirow[t]{2}{*}{ Alcohol use } & no & & & & 1.23 & & & & 0.93 \\
\hline & yes & 0.006 & 0.112 & 1.23 & & 0.006 & 0.088 & 0.931 & \\
\hline $\begin{array}{l}\text { Physical activity } \\
\text { (METs/hour/day) }\end{array}$ & & -0.298 & -0.017 & 9.42 & 9.42 & -0.706 & -0.017 & 22.742 & 22.74 \\
\hline \multirow[t]{14}{*}{ Province } & Fars & & & & 22.62 & & & & 56.19 \\
\hline & Guilan & 0.003 & -0.144 & -0.86 & & 0.015 & -0.138 & -3.871 & \\
\hline & $\begin{array}{l}\text { Sistan and } \\
\text { Baluchestan }\end{array}$ & -0.031 & -0.360 & 19.86 & & -0.056 & -0.384 & 40.266 & \\
\hline & Kermanshah & 0.003 & -0.063 & -0.385 & & 0.026 & -0.077 & -10.846 & \\
\hline & $\begin{array}{l}\text { Chaharmahal } \\
\text { and Bakhtiari }\end{array}$ & 0.005 & 0.157 & 1.31 & & 0.017 & 0.163 & 5.212 & \\
\hline & Mazandaran & -0.012 & 0.028 & -0.62 & & -0.013 & 0.022 & -0.517 & \\
\hline & Razavi Khorasan & 0.004 & 0.204 & 1.46 & & 0.015 & 0.206 & 5.735 & \\
\hline & Kerman & -0.003 & 0.285 & -1.62 & & 0.002 & 0.283 & 0.948 & \\
\hline & West Azarbaijan & 0.000 & -0.1860 & -0.08 & & 0.016 & -0.130 & -3.987 & \\
\hline & Hormozgan & 0.001 & 0.477 & 0.83 & & 0.002 & 0.441 & 1.353 & \\
\hline & Yazd & -0.005 & -0.060 & 0.58 & & -0.006 & -0.082 & 0.942 & \\
\hline & Khouzestan & 0.002 & -0.118 & -0.40 & & 0.008 & -0.121 & -1.749 & \\
\hline & East Azarbaijan & 0.010 & 0.266 & 4.66 & & 0.031 & 0.267 & 15.574 & \\
\hline & Ardabil & -0.003 & 0.602 & -3.07 & & -0.004 & 0.602 & -5.062 & \\
\hline \multirow[t]{5}{*}{$\begin{array}{l}\text { Socioeconomic } \\
\text { status (SES) }\end{array}$} & $\begin{array}{l}\text { 1st quintile } \\
\text { (the lowest) }\end{array}$ & & & & 66.77 & & & & 89.07 \\
\hline & 2nd quintile & 0.022 & -0.372 & -14.89 & & 0.037 & -0.362 & -24.913 & \\
\hline & 3rd quintile & 0.030 & 0.017 & 0.91 & & 0.054 & 0.051 & 5.136 & \\
\hline & 4th quintile & 0.038 & 0.398 & 27.32 & & 0.060 & 0.449 & 50.825 & \\
\hline & $\begin{array}{l}\text { 5th quintile } \\
\text { (the highest) }\end{array}$ & 0.037 & 0.794 & 53.43 & & 0.038 & 0.821 & 58.022 & \\
\hline
\end{tabular}


Table 2 Decomposition of socioeconomic inequality in overweight and obesity in the included population (Continued)

\begin{tabular}{|c|c|c|c|c|c|c|c|c|}
\hline \multirow[t]{2}{*}{ Variables } & \multicolumn{4}{|c|}{ Overweight } & \multicolumn{4}{|l|}{ Obesity } \\
\hline & Elasticity & $\begin{array}{l}\text { Concentration } \\
\text { index }\left(C_{k}\right)\end{array}$ & $\begin{array}{l}\text { percentage } \\
\text { contribution }\end{array}$ & $\begin{array}{l}\text { Summed } \\
\text { Percentage } \\
\text { Contribution }\end{array}$ & Elasticity & $\begin{array}{l}\text { concentration } \\
\text { Index }\left(C_{k}\right)\end{array}$ & $\begin{array}{l}\text { percentage } \\
\text { contribution }\end{array}$ & $\begin{array}{l}\text { Summed } \\
\text { Percentage } \\
\text { Contribution }\end{array}$ \\
\hline Explained & & & & 110.00 & & & & 221.28 \\
\hline Residuals & & & & -10.00 & & & & -121.28 \\
\hline Total & & & & 100.00 & & & & 100.00 \\
\hline
\end{tabular}

Note: $\mathrm{MET}=$ Metabolic Equivalent of Task

population. Socioeconomic differences can affect the contribution of the variables in the inequality of obesity. For example, in bilger's et al. (2017) study, Age was the largest contributor to the positive socioeconomic inequality among the participants [59]. Also, they found no socioeconomic inequality in obesity for Mexican Hispanics.

Additionally, region of residence and physical activity were the second and third positive contributors to the socioeconomic inequalities in overweight and obesity among the participants. With respect to these findings, the variation of outcome variables between the study provinces can increase socioeconomic inequality in overweight and obesity. As above mentioned, the result may be due to different lifestyle and dietary habits between the study provinces. Also, the positive contribution of physical activity shows that overweight and obesity are distributed disproportionally between individuals with different levels of physical activity. This finding can show a reverse causality between BMI and physical activity so that as participants gain weight, they tend to become less physically active.

It should be noted that marital status made a positive contribution to socioeconomic inequality in overweight and obesity as well. The finding demonstrates that married adults were more likely to be rich and obese than single individuals. The finding is consistent with the results of other studies in Iran [23, 25, 50, 61-63], which revealed a higher probability of obesity among both married women and men in comparison with single adults. In consistent with our findings, Studies suggested changes in the lifestyle and nutrition patterns after marriage as one of the factors to the higher BMI among adults. For example, the findings of Azadbakht et al. (2005) indicated that the percentage of energy and fat intake was higher among married people compared to single persons [21]. Also, Sartorius et al. (2015) found that single people spent more time exercising compared to married people [64].

In the present study, sex made a negative contribution to socioeconomic inequality in overweight among the participants. This negative contribution is the result of both the negative $\mathrm{CI}$ for females and the positive elasticity of all measures of obesity with respect to sex. Similar to previous studies in Iran $[65,66]$, our results suggested females are more likely to be obese than males. Sedentary lifestyle of women $[49,63,66,67]$ was regarded as one of the main factors contributing to the higher BMI among women in the study population. In the past studies, other factors such as unemployment, depression, unhealthy nutrition patterns, sleep disorders, and illiteracy, low SES, number of pregnancy, and lack of physical activity have identified as the risk factors of obesity among women [68].

Overall, our findings suggest that the burden of overweight and obesity be disproportionately borne by individuals with higher SES. Accordingly, it seems that intersectional actions should be taken to control and prevent overweight and obesity among higher socioeconomic groups. Given that women were more likely to be rich and obese, researchers need to identify the risk factors of obesity among different socioeconomic groups. Because in each group, the risk factors of obesity may be different from the other.

\section{Limitations}

The present study faced some limitations. This study was a cross-sectional analysis of a longtidutional cohort study that shows the measurements only for a time point, not a period. Also, data for all provinces and people under age 35 had not been included in PERSIAN cohort study. Given the positive relationship between age and obesity [69], the nonparticipation of individuals younger than 35 years may result in a higher prevalence of obesity among the cohort population. Third, our findings in the cohort population, may not be representative of the whole population of the study provinces because our data has been collected only in one or two cohort centers in each province. Forth, regarding that the information on drug abuse, alcohol consumption and hookah smoking were measured by a self-report questionnaire, probability of social desirability bias in our reported measures may be unavoidable. Given that 
Table 3 The cohort population in the study provinces

\begin{tabular}{|c|c|c|c|c|c|c|}
\hline Row & Province & *Population & Cohort site & *Population & Cohort population & Main Ethnicities \\
\hline 1 & Ardabil & $1,270,420$ & Ardabil & 529,374 & 8192 & Turk \\
\hline 2 & Chaharmahal and Bakhtiari & 947,763 & Sharekord & 93,104 & 6664 & Lor \\
\hline 3 & East Azerbaijan & $3,909,652$ & Khameneh & 3056 & 14,978 & Turk, Azari \\
\hline \multirow[t]{3}{*}{4} & \multirow[t]{3}{*}{ Fars } & \multirow[t]{3}{*}{$4,851,274$} & Kavar & 31,711 & 2244 & Fars (Persian), Turk \\
\hline & & & Kharameh & 18,477 & 10,662 & Fars (Persian), Arab \\
\hline & & & Fasa & 110,825 & 10,113 & Fars (Persian), Arab and Turk \\
\hline 5 & Guilan & $2,530,696$ & Some'e Sara & 58,658 & 10,511 & Gilaki \\
\hline 6 & Hormozgan & $1,776,415$ & Bandare Kong & 19,213 & 3570 & Arab \\
\hline 7 & Kerman & $3,164,718$ & Rafsanjan & 161,909 & 9982 & Fars (Persian) \\
\hline 8 & Kermanshah & $1,952,434$ & Ravansar & 47,657 & 10,077 & Kurd \\
\hline 9 & Khouzestan & $4,710,506$ & Hoveizeh & 19,481 & 9156 & Arab \\
\hline 10 & Mazandaran & $3,283,582$ & Sari & 309,820 & 10,253 & Tabari \\
\hline \multirow[t]{2}{*}{11} & \multirow[t]{2}{*}{ Razavi Khorasan } & \multirow[t]{2}{*}{$6,434,501$} & Mashhad & $3,001,184$ & 2189 & Fars (Persian) \\
\hline & & & Sabzevar & 243,700 & 784 & Fars (Persian) \\
\hline 12 & Sistan and Balouchestan & $2,775,014$ & Zahedan & 587,730 & 8318 & Balouch \\
\hline 13 & West Azerbaijan & $3,265,219$ & Ghoushchi & 2787 & 3662 & Turk, Azari \\
\hline 14 & Yazd & $1,138,533$ & Shahedieh, Yazd & 18,309 & 9901 & Fars (Persian) \\
\hline
\end{tabular}

*The frequency of population is according to Iranian Population and Housing Census in 2016 [70]

obesity derived from a combination of causes and contributing factors, we are not able to have a casual inference in obesity. Different factors such as environment features, ethnic groups, dietary patterns, family history of obesity, and family size may contribute to inequality in obesity that can be investigated in future studies.

\section{Conclusion}

Overall, our results showed that overweight and obesity were concentrated among well-off adults in the study population. Accordingly, it seems that intersectional actions should be taken to control and prevent overweight and obesity among higher socioeconomic groups.

\section{Abbreviations}

BMI: Body Mass Index:" Cl: Confidence Interval; $C_{n}$ : Concentration Index; METs: Metabolic Equivalent Rates; NHIS: National Health Interview Survey; PCA: Principal Component Analysis; PERSIAN: Prospective Epidemiologic Research Studies in IrAN; SES: Socioeconomic Status; WHO: World Health Organization

\section{Acknowledgements}

The authors would like to thank all people who participated in the PERSIAN cohort study, and all staff members for collaborating in data collection.

\section{Authors' contributions}

FN: Contributed in the design of the work, analysis and interpretation of the results, writing and revising the full manuscript; SS: Contributed in the design of the work, analyzing the data, writing and revising the full manuscript, BKM: Contributed in the design of the work, analyzing the data, and revising the manuscript; AKK: Contributed in the design of the work, analyzing the data and interpreting the results; SR: Contributed in the design of the work and analyzing the data; MS: Contributed in design of the work, analyzing the data and interpreting the results; YS: Contributed in the design of the study and interpreting the results; MM1: Contributed in cleaning and analyzing the data; $\mathrm{MH}$ : Contributed in the design of the study and writing the manuscript; LB: Contributed in analyzing data and creating the maps; YP: Contributed in the design of the work, collecting and analyzing the data; BH: Contributed in the design of the study and collecting the data; AAH: contributed in analyzing the data and interpreting the results; RM: Contributed in collecting data; HP: Contributed in collecting data; SE: Contributed in collecting data; AN: Contributed in collecting data; MM2: Contributed in collecting data; MJZS: Contributed in collecting data; FJ: Contributed in collecting data; SMHS: Contributed in collecting data; AV: Contributed in collecting data; RN: Contributed in collecting data; EF: Contributed in collecting data; GAA: Contributed in collecting data; FG: Contributed in collecting data; AK: Contributed in collecting data; DV: Contributed in collecting data; $\mathrm{RH}$ : Contributed in collecting data; ARS: Contributed in collecting data; SVH: Contributed in collecting data; RR: Contributed in collecting data; SAH: Contributed in collecting data. All authors read and approved the submitted version and modified version of the manuscript. Also, all authors agreed both to be personally accountable for the author's own contributions and to ensure that questions related to the accuracy or integrity of any part of the work are appropriately investigated, resolved, and the resolution documented in the literature.

\section{Funding}

This study used the data obtained from the PERSIAN (Prospective Epidemiological Research Studies in IrAN) Cohort study in Iran. Iran's Ministry of Health and Medical Education has contributed to the funding used in The PERSIAN Cohort through Grant no. 700/534.

\section{Availability of data and materials}

Data and all other materials for this study are kept at the deputy of research and technology of Kermanshah University of Medical Sciences. The datasets generated and/or analyzed during the current study are not publicly available due the terms of consent to which the participants agreed but are available from the corresponding author on reasonable request. 


\section{Ethics approval and consent to participate}

While each cohort center received the ethical approval from local universities, for the purpose of this study and pooling all PERSIAN data, the ethics committee of Kermanshah University of Medical Sciences approved the study (IR.KUMS.REC.1397.866).

\section{Consent for publication}

Not applicable.

\section{Competing interests}

The authors declare no conflict of interest.

\section{Author details}

'Research Center for Environmental Determinants of Health, Health Institute, Kermanshah University of Medical Sciences, Kermanshah, Iran. ${ }^{2}$ Social Development and Health Promotion Research Center, Kermanshah University of Medical Sciences, Kermanshah, Iran. ${ }^{3}$ School of Health Administration, Faculty of Health, Dalhousie University, Halifax, Canada. ${ }^{4}$ Modeling in Health Research Center, Institute for Future Studies in Health, Kerman University of Medical Sciences, Kerman, Iran. ${ }^{5}$ Liver and pancreatobiliary Diseases Research Center, Digestive Diseases Research Institute, Tehran University of Medical Sciences, Tehran, Iran. ${ }^{6}$ Molecular Medicine Research Center, Hormozgan University of Medical Sciences, Bandar Abbas, Iran. ${ }^{7}$ Health Sciences Research Center, Addiction Institute, Mazandaran University of Medical Sciences, Sari, Iran. ${ }^{8}$ Occupational Health Research Centre, School of Public Health, Shahid Sadoughi University of Medical Sciences, Yazd, Iran. ${ }^{9}$ Gastrointestinal and Liver Diseases Research Center, Guilan University of Medical Sciences, Rasht, Iran. ${ }^{10}$ Health Promotion Research Center, Zahedan University of Medical Sciences, Zahedan, Iran. ${ }^{11}$ Dept. of Neurology, Medical School, Rafsanjan University of Medical Sciences, Rafsanjan, Iran. ${ }^{12}$ Gastroenterohepatology Research Center, Shiraz University of Medical Sciences, Shiraz, Iran. ${ }^{13}$ Liver and Gastrointestinal Diseases Research Center, Tabriz University of Medical sciences, Tabriz, Iran. ${ }^{14}$ Digestive Disease Research Center, Ardabil University of Medical Sciences, Ardabil, Iran. ${ }^{15}$ Traditional and Complementary Medicine Research Center, Sabzevar University of Medical Sciences, Sabzevar, Iran. ${ }^{16}$ Modeling in Health Research Center, Shahrekord University of Medical Sciences, Shahrekord, Iran. ${ }^{17}$ Social Determinants of Health Research Center, Urmia University of Medical Sciences, Urmia, Iran. ${ }^{18}$ Noncommunicable Diseases Research Center, Fasa University of Medical Sciences, Fasa, Iran. ${ }^{19}$ Colorectal Research Center, Shiraz University of Medical Sciences, Shiraz, Iran. ${ }^{20}$ Department of Nutrition, Faculty of Medicine, Mashhad University of Medical Sciences, Mashhad, Iran. ${ }^{21}$ Nutrition and Metabolic Diseases Research Center, Ahvaz Jundishapur University of Medical Sciences, Ahvaz, Iran.

Received: 18 September 2019 Accepted: 5 February 2020

Published online: 11 February 2020

\section{References}

1. Singh GM, Danaei G, Farzadfar F, Stevens GA, Woodward M, Wormser D, et al. The age-specific quantitative effects of metabolic risk factors on cardiovascular diseases and diabetes: a pooled analysis. PLoS One. 2013;8(7):e65174.

2. Czernichow S, Kengne AP, Stamatakis E, Hamer M, Batty GD. Body mass index, waist circumference and waist-hip ratio: which is the better discriminator of cardiovascular disease mortality risk? Evidence from an individual-participant meta-analysis of 82864 participants from nine cohort studies. Obes Rev. 2011;12(9):680-7.

3. Lauby-Secretan B, Scoccianti C, Loomis D, Grosse Y, Bianchini F, Straif K. Body fatness and cancer-viewpoint of the IARC working group. N Engl J Med. 2016;375(8):794-8.

4. Anandacoomarasamy A, Caterson I, Sambrook P, Fransen M, March L. The impact of obesity on the musculoskeletal system. Int J Obes. 2008; 32(2):211-22.

5. Anstey $K$, Cherbuin N, Budge M, Young J. Body mass index in midlife and late-life as a risk factor for dementia: a meta-analysis of prospective studies. Obes Rev. 2011;12(5):e426-e37.

6. Kushner RF, Foster GD. Obesity and quality of life. Nutrition. 2000;16(10): 947-52.

7. Goettler A, Grosse A. Sonntag D. Productivity loss due to overweight and obesity: a systematic review of indirect costs. 2017;7(10):e014632.
8. Hill JO, Peters JC, Catenacci VA, Wyatt HR. International strategies to address obesity. Obesity reviews : an official journal of the International Association for the Study of Obesity. 2008;9(Suppl 1):41-7.

9. World Health Organization. WORLD HEALTH STATISTICS. France. 2008:2008.

10. Lakerveld J, Mackenbach J. The upstream determinants of adult obesity. Obesity facts. 2017;10(3):216-22.

11. Harding JL, Backholer K, Williams ED, Peeters A, Cameron AJ, Hare MJ, et al. Psychosocial stress is positively associated with body mass index gain over 5 years: evidence from the longitudinal AusDiab study. Obesity (Silver Spring, Md). 2014;22(1):277-86.

12. Patel SR, Hu FB. Short sleep duration and weight gain: a systematic review. Obesity (Silver Spring, Md). 2008;16(3):643-53.

13. Affenito SG, Franko DL, Striegel-Moore RH, Thompson D. Behavioral determinants of obesity: research findings and policy implications. J Obes. 2012;2012:150732

14. Block JP, He Y, Zaslavsky AM, Ding L, Ayanian JZ. Psychosocial stress and change in weight among US adults. Am J Epidemiol. 2009;170(2):181-92.

15. Kiecolt-Glaser JK, Newton TL. Marriage and health: his and hers. Psychol Bull. 2001;127(4):472-503.

16. Zamani Sani SH, Eskandarnejad M, Fathirezaie Z. Body image, perceived physical fitness, physical activity, body mass index and age in women. Women Health Bull. 2016;3(3):e31886.

17. Dinsa GD, Goryakin Y, Fumagalli E, Suhrcke M. Obesity and socioeconomic status in developing countries: a systematic review. Obesity reviews : an official journal of the International Association for the Study of Obesity. 2012;13(11):1067-79.

18. McLaren L. Socioeconomic status and obesity. Epidemiol Rev. 2007;29:29-48.

19. Kuntz B, Lampert T. Socioeconomic factors and obesity. Deutsches Arzteblatt international. 2010;107(30):517-22.

20. Cohen AK, Rai M, Rehkopf DH. Abrams B. Educational attainment and obesity: a systematic review. 2013;14(12):989-1005.

21. Azadbakht M, Shiva A. General obesity and central adiposity in a representative sample of Tehranian adults: prevalence and determinants. Int J Vitam Nutr Res. 2005;75(4):297-304.

22. Bakhshi E, Eshraghian MR, Mohammad K, Foroushani AR, Zeraati H, Fotouhi A, et al. Sociodemographic and smoking associated with obesity in adult women in Iran: results from the National Health Survey. Journal of public health (Oxford, England). 2008;30(4):429-35.

23. Hajian-Tilaki KO, Heidari B. Prevalence of obesity, central obesity and the associated factors in urban population aged 20-70 years, in the north of Iran: a population-based study and regression approach. Obes Rev. 2007:8(1):3-10

24. Kolahi A-A, Moghisi A, Soleiman EY. Socio-demographic determinants of obesity indexes in Iran: findings from a nationwide STEPS survey. Health promotion perspectives. 2018;8(3):187-94.

25. Najafi F, Pasdar Y, Hamzeh B, Rezaei S, Moradi Nazar M, Soofi M. Measuring and decomposing socioeconomic inequalities in adult obesity in Western Iran. Journal of preventive medicine and public health $=$. Yebang Uihakhoe chi. 2018;51(6):289-97.

26. Raeisi A, Mehboudi M, Darabi H, Nabipour I, Larijani B, Mehrdad N, et al. Socioeconomic inequality of overweight and obesity of the elderly in Iran: Bushehr elderly health (BEH) program. BMC Public Health. 2017;17(1):72.

27. Eghtesad S, Mohammadi Z, Shayanrad A, Faramarzi E, Joukar F, Hamzeh B, et al. The PERSIAN cohort: providing the evidence needed for healthcare reform. Archives of Iranian medicine. 2017;20(11):691-5.

28. Poustchi H, Eghtesad S, Kamangar F, Etemadi A, Keshtkar AA, Hekmatdoost A, et al. Prospective epidemiological research studies in Iran (the PERSIAN cohort study): rationale, objectives, and design. Am J Epidemiol. 2018;187(4):647-55.

29. World Health Organization. Physical Status: The Use and Interpretation of Anthropometry. Report of a World Health Organization (WHO) Expert Committee. Geneva, Switzerland: World Health Organization; 1998.

30. Jette M, Sidney K, Blumchen G. Metabolic equivalents (METS) in exercise testing, exercise prescription, and evaluation of functional capacity. Clin Cardiol. 1990;13(8):555-65.

31. Ainsworth BE, Haskell WL, Herrmann SD, Meckes N, Bassett DR Jr, TudorLocke C, et al. 2011 compendium of physical activities: a second update of codes and MET values. Med Sci Sports Exerc. 2011:43(8):1575-81.

32. Kazemi Karyani A, Karmi Matin B, Soltani S, Rezaei S, Soofi M, Salimi Y, et al. Socioeconomic gradient in physical activity: findings from the PERSIAN cohort study. BMC Public Health. 2019;19(1):1312. 
33. The Centers for Disease Control and Prevention. Glossary - Alcohol [Available from: https://www.cdc.gov/nchs/nhis/alcohol/alcohol_ glossary.htm.

34. The Centers for Disease Control and Prevention. National Health Interview Survey [Available from: https://www.cdc.gov/nchs/nhis/tobacco/tobacco_ glossary.htm.

35. The Centers for Disease Control and Prevention. Hookahs [Available from: https://www.cdc.gov/tobacco/data_statistics/fact_sheets/tobacco_industry/ hookahs/index.htm.

36. Poirier MJP, Grépin KA, Grignon M. Approaches and alternatives to the wealth index to measure socioeconomic status using survey data: a critical interpretive synthesis. Soc Indic Res. 2019.

37. Mohsena M, Mascie-Taylor CGN, Goto R. Association between socioeconomic status and childhood undernutrition in Bangladesh; a comparison of possession score and poverty index. Public Health Nutr. 2010;13(10):1498-504.

38. Nwaru Bl, Klemetti R, Kun H, Hong W, Yuan S, Wu Z, et al. Maternal socioeconomic indices for prenatal care research in rural China. Eur J Pub Health. 2011;22(6):776-81.

39. Chuma J, Molyneux C. Estimating inequalities in ownership of insecticide treated nets: does the choice of socio-economic status measure matter? Health Policy Plan. 2009;24(2):83-93.

40. Afifi M. Wealth index association with gender issues and the reproductive health of Egyptian women. Nursing \& Health Sciences. 2009;11(1):29-36.

41. Booysen F, van der Berg S, Burger R. Maltitz mv, Rand Gd. Using an asset index to assess trends in poverty in seven sub-Saharan African countries. World Dev. 2008;36(6):1113-30

42. Filmer D, Pritchett LH. Estimating wealth effects without expenditure data_or tears: an application to educational enrollments in states of India*. Demography. 2001;38(1):115-32.

43. Kazemi Karyani A, Rezaei S, Karami Matin B, Amini S. Poor health-related quality of life in Iran: decomposition analysis of affecting factors. International Journal of Human Rights in Healthcare. 2018.

44. O'Donnell O, O'Neill S, Van Ourti T, Walsh B. Conindex: estimation of concentration indices. Stata J. 2016;16(1):112-38.

45. Walsh B, Cullinan J, Biology H. Decomposing socioeconomic inequalities in childhood obesity: evidence from Ireland. Econ Hum Biol. 2015;16:60-72.

46. Wagstaff $A$. The bounds of the concentration index when the variable of interest is binary, with an application to immunization inequality. Health Econ. 2005;14(4):429-32.

47. Wagstaff A, Van Doorslaer E, Watanabe N. On decomposing the causes of health sector inequalities with an application to malnutrition inequalities in Vietnam. J Econom. 2003;112(1):207-23.

48. Malik V, Hu F. Cardiovascular, Respiratory, and Related Disorders. 3rd edition Washington (DC): The International Bank for Reconstruction and Development / The World Bank; 2017 [Available from: https://www.ncbi. nlm.nih.gov/books/NBK525156/figure/ch7.sec4.fig 1/.

49. N. Mohammadi MS, F. Shobeiri PD, A. Khirollahi MSs. Frequency of over Wieght \& Obesity of women in referents to medical and health centers in Hamadam City. Scientific Journal of Hamadan Nursing \& Midwifery Faculty 2011;19(2):36-46.

50. Moghimi-Dehkordi B, Safaee A, Vahedi M, Pourhoseingholi A, Pourhoseingholi M, Ashtari S, et al. Overweight and obesity and related factors in urban Iranian population aged between 20 to 84 years. Annals of medical and health sciences research. 2013;3(2):171-6.

51. Faghih Sh, Taleban F, Abadi A, Ansari N. Trends of overweight and obesity among 14-18 years old urban adolescent girls among senior high schools, Ahvaz, Iran. 2009.

52. Vakili M, Abedi $P$, Sharifi M, Hosseini M. Dietary diversity and its related factors among adolescents: a survey in Ahvaz-Iran. Glob J Health Sci. 2013:5(2):181-6.

53. Sharifi A, Amani R, Hamidipour N. Prevalence of Obesity and its Related Lifestyle Pattern in Male Personnel of Jundi-Shapour University of Medical Sciences - 2005\%J Iranian Journal of Endocrinology and Metabolism. 2008;10(3):235-9.

54. Masoudi M, Elhaeesahar M. Trend assessment of climate changes in Khuzestan Province. Iran Natural Environment Change. 2016;2(2):143-52.

55. Hayes A, Tan EJ, Killedar A. Lung T. Socioeconomic inequalities in obesity: modelling future trends in Australia. 2019;9(3):e026525.
56. Alaba O, Chola L. Socioeconomic inequalities in adult obesity prevalence in South Africa: a decomposition analysis. Int J Environ Res Public Health. 2014;11(3):3387-406.

57. Hwang J, Lee E-Y, Lee CG. Measuring socioeconomic inequalities in obesity among Korean adults, $1998^{-}$2015. Int J Environ Res Public Health. 2019; 16(9):1617.

58. Kelishadi R, Alikhani S, Delavari A, Alaedini F, Safaie A, Hojatzadeh E. Obesity and associated lifestyle behaviours in Iran: findings from the first National non-communicable Disease Risk Factor Surveillance Survey. Public Health Nutr. 2008;11(3):246-51.

59. Bilger M, Kruger EJ, Finkelstein EA. Measuring socioeconomic inequality in obesity: looking beyond the obesity threshold. Health Econ. 2017;26(8):1052-66

60. Goodarzi MO. Genetics of obesity: what genetic association studies have taught us about the biology of obesity and its complications. The Lancet Diabetes \& Endocrinology. 2018;6(3):223-36.

61. Bakhshi E, Eshraghian MR, Mohammad K, Foroushani AR, Zeraati H, Fotouhi A, et al. Sociodemographic and smoking associated with obesity in adult women in Iran: results from the national health survey. J Public Health. 2008;30(4):429-35.

62. Karimbeiki R, Safavi M, Feizi A, Abbasi B, Nikpour M. The relationship between dietary diversity score and obesity in Tehranian adults: a case-control study. Iranian Journal of Endocrinology and Metabolism. 2016;18(4):260-9.

63. Pasdar Y, Darbandi M, Niazi P, Alghasi S, Roshanpour F. The prevalence and the affecting factors of obesity in women of Kermanshah. Jorjani Biomedicine Journal. 2015;3(1):82-97.

64. Sartorius B, Veerman LJ, Manyema M, Chola L, Hofman K. Determinants of Obesity and Associated Population Attributability, South Africa: Empirical Evidence from a National Panel Survey, 2008-2012. PloS one. 2015;10(6):e0130218-e.

65. Mehboudi MB, Raeisi A, Najaf F, Mosadeghzadeh S, Nabipour I, Darabi H, et al. The incidence and prevalence of obesity and overweight in adults during 2003 to 2009 in Bushehr Province- the Persian Gulf healthy heart study. Iranian South Medical Journal. 2015;18(2):409-20.

66. Barzin M, Hosseinpanah F, Arzhan S, Azizi F. Trends of obesity and abdominal obesity in Tehranian adults (1999-2008). Pajoohande. 2011;16(5):212-8

67. Bakhshi E, Mohammad K, Eshraghian MR, Seifi B. Factors related to obesity among Iranian men: results from the National Health Survey. Public Health Nutr. 2010;13(9):1389-94

68. Audrain-McGovern J, Benowitz NL. Cigarette smoking, nicotine, and body weight. Clin Pharmacol Ther. 2011;90(1):164-8.

69. Tabrizi JS, Sadeghi-Bazargani H, Farahbakhsh M, Nikniaz L, Nikniaz Z. Prevalence and associated factors of overweight or obesity and abdominal obesity in Iranian population: a population-based study of northwestern Iran. Iran J Public Health. 2018;47(10):1583-92.

70. Statistical Center of Iran. 2016 [Available from: https://www.amar.org.ir/ english/Population-and-Housing-Censuses.

\section{Publisher's Note}

Springer Nature remains neutral with regard to jurisdictional claims in published maps and institutional affiliations.

Ready to submit your research? Choose BMC and benefit from:

- fast, convenient online submission

- thorough peer review by experienced researchers in your field

- rapid publication on acceptance

- support for research data, including large and complex data types

- gold Open Access which fosters wider collaboration and increased citations

- maximum visibility for your research: over $100 \mathrm{M}$ website views per year

At BMC, research is always in progress.

Learn more biomedcentral.com/submissions 